INTERSTITIAL LUNG DISEASE

\title{
Skeletal muscle weakness in patients with sarcoidosis and its relationship with exercise intolerance and reduced health status
}

\author{
M A Spruit, M J Thomeer, R Gosselink, T Troosters, A Kasran, A J T Debrock, M G Demedts, \\ M Decramer
}

Thorax 2005;60:32-38. doi: 10.1136/thx.2004.022244

See end of article for authors' affiliations .........

Correspondence to: Professor M Decramer, Respiratory Rehabilitation, University Hospital Gasthuisberg, Herestraat 49, B-3000, Leuven, Belgium; Marc.Decramer@ uz.kuleuven.ac.be

Received 26 January 2004 Accepted 28 May 2004

\begin{abstract}
Background: Skeletal muscle weakness is assumed to be present in patients with sarcoidosis but has never been reported in a consecutive group of patients. Moreover, its relationship with previously observed exercise intolerance and reduced health status has never been studied in these patients.

Methods: Pulmonary function, skeletal and respiratory muscle forces, peak and functional exercise capacity, health status, and the circulating levels of inflammatory and anabolic markers were determined in 25 patients with sarcoidosis who complained of fatigue (15 men) and in 21 healthy subjects (13 men). Results: Patients with sarcoidosis had lower respiratory and skeletal muscle forces, reduced exercise capacity and health status, higher anxiety and depression scores, and higher circulating levels of tumour necrosis factor- $\alpha$ than healthy subjects (all $p \leqslant 0.01$ ). Its soluble receptor $p 75$ tended to be higher $(p=0.04)$. Circulating levels of interleukin (IL)-6, IL-8, insulin-like growth factor I and its binding protein 3 were not significantly different between the two groups. Skeletal muscle weakness was related to exercise intolerance, depression, and reduced health status in patients with sarcoidosis, irrespective of age, sex, body weight and height $(p \leqslant 0.05)$. Quadriceps peak torque was inversely related to fatigue but not to the circulating levels of inflammatory or anabolic markers. The mean daily dose of corticosteroids received in the 6 month period before testing was related to quadriceps peak torque only in patients who received oral corticosteroids.

Conclusion: Skeletal muscle weakness occurs in patients with sarcoidosis who complain of fatigue and is associated with reduced health status and exercise intolerance.
\end{abstract}

S arcoidosis is a heterogeneous multisystem disorder of unknown aetiology which often presents with bilateral hilar lymphadenopathy, pulmonary infiltration, and ocular and skin lesions. ${ }^{1}$ In addition to possible changes in forced vital capacity (FVC) and carbon monoxide transfer factor (TLCO), a higher prevalence of clinical depression, ${ }^{23}$ reduced health status ${ }^{3-5}$ and exercise intolerance ${ }^{6-10}$ have been observed in patients with sarcoidosis.

Reduced health status has been related to decreased pulmonary function, ${ }^{4}$ depressive symptoms, ${ }^{3}$ and to respiratory muscle weakness. ${ }^{5}$ Exercise capacity is believed to be limited by dyspnoea, an insufficient heart rate response, decreased arterial oxygen tension during exercise, excessive and inefficient ventilation, and by respiratory muscle weakness. ${ }^{5810}$ In the past exercise capacity was shown to be limited by skeletal muscle weakness in patients with chronic pulmonary or cardiac disease. ${ }^{11}{ }^{12}$ The possible contribution of skeletal muscle weakness to exercise intolerance has never been studied in patients with sarcoidosis. Although Wirnsberger et $a l^{5}$ found that quadriceps muscle force and handgrip force of patients with sarcoidosis were not significantly different from healthy subjects, $67 \%$ of the sarcoidosis patients studied by Miller et al terminated their peak exercise test due to "leg complaints". ${ }^{9}$ Skeletal muscle weakness is therefore still assumed to be present in patients with sarcoidosis. ${ }^{1}$ Treatment with oral corticosteroids, ${ }^{13}$ clinical symptoms of depression, ${ }^{23}$ myositis, ${ }^{14}$ self-reported complaints of fatigue, ${ }^{15}$ and high circulating levels of tumour necrosis factor- $\alpha(\mathrm{TNF}-\alpha)^{16}$ are all present in patients with sarcoidosis and can all affect skeletal muscle force and exercise capacity. ${ }^{17-22}$ Additionally, low levels of circulating insulin-like growth factor I (IGF-I), which can be induced by high levels of $\mathrm{TNF}-\alpha,{ }^{23}$ and high circulating levels of interleukin (IL)-6 and IL-8 (CXCL8) have been associated with skeletal muscle weakness. ${ }^{24} 25$ These interleukins are part of the current concept of the immunopathogenesis of sarcoidosis $^{16}$ and may be raised in patients with stable sarcoidosis. ${ }^{26}$

Based on these findings, we reasoned that skeletal muscle weakness may be present in patients with sarcoidosis who complain of fatigue and may be related to exercise capacity, symptoms, and to health status. A cross sectional comparative study was therefore undertaken to investigate three questions:

- Is skeletal muscle weakness present in sarcoidosis patients with fatigue compared with healthy control subjects?

- What is the relationship between skeletal muscle force and exercise capacity and health status?

- What is the relationship between skeletal muscle force and circulating levels of inflammatory and anabolic markers and the use of oral corticosteroids?

\section{METHODS}

\section{Participants}

Twenty nine consecutive patients with sarcoidosis who spontaneously complained of fatigue at the outpatient interstitial lung disease clinic in a tertiary care setting (without being asked by the pulmonary physicians) received information about the survey and were invited to participate. Sarcoidosis had been previously diagnosed according to the 
latest ATS/ERS/WASOG statement on sarcoidosis. ${ }^{1}$ Twenty five patients agreed to participate, of which 22 were eligible for statistical analyses. One patient with clinical symptoms of severe cox arthrosis and two patients with electrocardiographic evidence of cardiac dysfunction during peak exercise were excluded. Sarcoidosis had been diagnosed a median of 4 years previously (IQR 2-7). Based on their chest radiographs, seven patients had stage I disease, six had stage II, and nine had stage III. $^{27}$ None of the patients had any significant medical history or co-morbidity except for one man who was known to have diabetes mellitus type 2. Fifty percent of the patients received oral corticosteroids in the 6 month period before testing at a mean dose of $1-32 \mathrm{mg}$ oral methylprednisolone equivalents per day.

Twenty one age and sex matched healthy subjects were recruited from relatives and friends by two students of the Faculty of Physical Education and Physiotherapy (table 1).

The ethics committee of the University Hospitals Leuven granted approval for the study. All participants were of white ethnic origin and gave oral and written informed consent.

\section{Blood analyses}

Venous blood was drawn from supine subjects between 08.30 and 09.00 hours before functional testing. IL- 6 and CXCL8 were determined using cytometric bead array, TNF- $\alpha$ and its soluble receptors (sTNF-R55 and sTNF-R75) were measured using enzyme linked immunoassays, IGF-I was determined using a radioimmunoassay as described previously, ${ }^{28}$ and IGF binding protein-3 (IGFBP-3) was assessed using an immunoradiometric assay.

\section{Functional tests}

Pulmonary function, respiratory muscle forces, handgrip force, quadriceps peak torque, and 6 minute walking distance were measured as described previously. ${ }^{12}{ }^{29}$ Peak exercise capacity was assessed by a maximal incremental cycle exercise test. After a 2 minute resting period and 3 minutes of unloaded cycling, participants started at 20 watts and cycled until symptom limitation at an incremental workload (+30 watt/2 minutes). At the end of the test Borg symptom scores for dyspnoea and fatigue were obtained from all participants. Peak external work rate and peak oxygen uptake were normalised for height, age, and sex..$^{30}$

\section{Questionnaires}

Health status was measured using the Medical Outcomes Study 36-Item Short-Form Health Survey $\left(\right.$ SF-36) ${ }^{31}$ and the EQ-5D (formerly the EuroQoL). ${ }^{32}$ The Hospital Anxiety and

Table 1 Characteristics of study subjects

\begin{tabular}{|c|c|c|}
\hline & Sarcoidosis & Healthy subjects \\
\hline $\operatorname{Sex}(M: F)$ & $14: 8$ & $13: 8$ \\
\hline Age (years) & $42(9)$ & $42(10)$ \\
\hline Smoking (never/ex/current) & $12 / 9 / 1$ & $11 / 7 / 3$ \\
\hline Height $(\mathrm{cm})$ & $172(9)$ & $172(9)$ \\
\hline $\mathrm{BMI}\left(\mathrm{kg} / \mathrm{m}^{2}\right)$ & $27(5)$ & $25(4)$ \\
\hline FVC (I) & 4.30 (1.37) & 4.81 (1.39) \\
\hline FVC (\% predicted) & 101 (19) & $114(16)$ \\
\hline $\mathrm{FEV}_{1} / \mathrm{FVC}(\%)$ & $77(8)$ & $79(7)$ \\
\hline $\operatorname{TLCO}(\mathrm{mmol} / \mathrm{min} / \mathrm{kPa})^{*}$ & $7.92(2.19)$ & $9.35(2.05)$ \\
\hline TLCO $(\% \text { predicted })^{\star *}$ & $77(15)$ & 93 (12) \\
\hline $\mathrm{PaO}_{2}(\mathrm{kPa})$ & $12.3(1.2)$ & $12.9(0.9)$ \\
\hline $\mathrm{PaCO}_{2}(\mathrm{kPa})^{* *}$ & $5.2(0.5)$ & $5.6(0.5)$ \\
\hline
\end{tabular}

Values are expressed as mean (SD) except for sex and smoking history (absolute numbers).

BMI, body mass index; FVC, forced vital capacity; FEV 1 , forced expiratory volume in 1 second; TLCO, carbon monoxide transfer factor; $\mathrm{PaO}_{2}$, arterial oxygen tension; $\mathrm{PaCO}_{2}$, arterial carbon dioxide tension. ${ }^{*} \mathrm{p}=0.03 ;{ }^{* *} \mathrm{p}<0.01$
Depression Scale (HADS) ${ }^{33}$ and the domain fatigue of the Chronic Respiratory Disease Questionnaire (CRDQ) ${ }^{34}$ were used to assess the presence of clinical symptoms of anxiety, depression and fatigue, respectively.

\section{Statistical analyses}

The results are presented as mean (SD) or median (interquartile range, IQR). A two tailed unpaired $t$ test (continuous), a Mann-Whitney $U$ test, or a $\chi^{2}$ test (binomial) was used to determine differences between sarcoidosis patients and healthy subjects. Differences between means and their 95\% confidence intervals (95\% CI) are reported. Moreover, differences between medians and their 95\% CI were calculated based on the resampling technique known as bootstrap. The number of replicates was set equal to $5000 .^{35} \mathrm{~A}$ priori, a two sided level of significance was set at $\mathrm{p} \leqslant 0.01 .^{36}$ Pearson product moment correlation (continuous, $r$ ) or Spearman rank correlation $\left(r_{\mathrm{S}}\right)$ were used to determine relationships in patients with sarcoidosis. A priori, a two sided level of significance was set at $p \leqslant 0.05 .{ }^{36}$

\section{RESULTS}

\section{Cross sectional comparisons}

Characteristics and functional tests

Patients with sarcoidosis generally had normal body mass index (BMI) and spirometric test results, mildly reduced TLCO (difference between means 15\% predicted (95\% CI 7 to 23 ), $\mathrm{p}=0.02$ ), normal $\mathrm{PaO}_{2}$ and $\mathrm{PaCO}_{2}$ (table 1), and lower respiratory and skeletal muscle force (table 2 ).

Functional and peak exercise capacity were lower in patients with sarcoidosis than in healthy subjects (table 2). On average, patients reached the limits of their cardiocirculatory system (defined as: 220 - age (expressed in years) \pm 15 beats per minute), accompanied by high Borg symptom scores for dyspnoea and fatigue (table 2). Patients and healthy subjects had comparable linear relationships between mean oxygen uptake and mean external work rate (oxygen consumption $=0.3985+0.0090 \times$ external work rate versus $0.3505+0.0095 \times$ external work rate, respectively). In contrast, the slope of the linear relationship between mean heart rate and mean oxygen consumption tended to be significantly steeper in patients with sarcoidosis $(p=0.09$, see fig Sl online).

\section{Circulating levels of inflammatory and anabolic markers}

Only the median circulating level of TNF- $\alpha$ was significantly higher in patients with sarcoidosis (24.1 pg/ml (IQR 20.2$30.5)$ ) than in healthy subjects ( $15.3 \mathrm{pg} / \mathrm{ml}$ (IQR 12.9-22.5)). Moreover, there was a tendency for sTNF-R75 to be higher in patients with sarcoidosis (median $4.35 \mathrm{ng} / \mathrm{ml}$ (IQR 3.834.95) than in healthy subjects (median $3.54 \mathrm{ng} / \mathrm{ml}$ (IQR $2.72-4.42), \mathrm{p}=0.04$ ). Complete results are shown in table $\mathrm{SI}$ in the online Appendix.

\section{Questionnaires}

Patients scored significantly worse on the CRDQ domain fatigue (median 15 points (IQR 11-17) than healthy subjects (median 24 (IQR 23-26), $\mathrm{p}=0.0001$; difference between medians 9 points (95\% CI 7 to 13)). Compared with healthy subjects, the health status of patients with sarcoidosis was significantly lower (table 3). Patients reported some or severe problems with performing usual activities and more pain and discomfort on the EQ-5D than healthy subjects (table 3). Patients had significantly higher median scores for anxiety and depression on the HADS (table 3 ); $24 \%$ of the patients scored above the cut off score of 10 points for clinical anxiety and $38 \%$ for depression. No healthy subject scored $\geqslant 10$ points. 
Table 2 Muscle force and exercise capacity in patients with sarcoidosis and healthy subjects

\begin{tabular}{|c|c|c|c|c|}
\hline & Sarcoidosis & Healthy subjects & $\begin{array}{l}\text { Differences between } \\
\text { means }(95 \% \mathrm{Cl})\end{array}$ & $p$ value \\
\hline \multicolumn{5}{|l|}{ Muscle force } \\
\hline PImax $\left(\mathrm{cm} \mathrm{H}_{2} \mathrm{O}\right)$ & $-89(31)$ & $-115(33)$ & $-26(-45$ to -5$)$ & 0.01 \\
\hline PImax (\% predicted) & $79(21)$ & $104(28)$ & $25(10$ to 40$)$ & 0.002 \\
\hline Pemax $\left(\mathrm{cm} \mathrm{H}_{2} \mathrm{O}\right)$ & $157(53)$ & $205(53)$ & 49 (16 to 81$)$ & 0.004 \\
\hline PEmax (\% predicted) & $84(20)$ & $112(19)$ & 28 (16 to 40 ) & 0.0001 \\
\hline HGF (kgF) & $38(13)$ & $45(13)$ & $7(-1$ to 16$)$ & 0.07 \\
\hline HGF (\% predicted) & $87(22)$ & $104(16)$ & 17 (5 to 28 ) & 0.007 \\
\hline QPT $(\mathrm{Nm})$ & $142(62)$ & $187(56)$ & $45(9$ to 81$)$ & 0.02 \\
\hline QPT (\% predicted) & $67(22)$ & $95(16)$ & 29 (17 to 41$)$ & 0.0001 \\
\hline \multicolumn{5}{|l|}{ Functional exercise test } \\
\hline $6 M W D(m)$ & 605 (131) & $788(106)$ & 183 (109 to 256$)$ & 0.0001 \\
\hline 6MWD (\% predicted) & $79(13)$ & $102(11)$ & $23(16$ to 31$)$ & 0.0001 \\
\hline Dyspnoea 6MWD (points) & $3.7(1.8)$ & $1.9(1.2)$ & $-1.8(-2.7$ to -0.8$)$ & 0.0006 \\
\hline Fatigue 6MWD (points) & $4.6(2.5)$ & 3.6 (1.7) & $-0.9(-2.2$ to 0.4$)$ & 0.18 \\
\hline \multicolumn{5}{|l|}{ Peak exercise test } \\
\hline Peak load (watt) & $165(54)$ & $230(72)$ & 65 (26 to 104$)$ & 0.002 \\
\hline Peak load (\% predicted) & 84 (17) & $123(22)$ & 40 (28 to 52 ) & 0.0001 \\
\hline Peak $\mathrm{VO}_{2}(\mathrm{ml} / \mathrm{kg} / \mathrm{min})$ & $25(9)$ & $36(10)$ & 11 (5 to 17$)$ & 0.001 \\
\hline Peak $\mathrm{VO}_{2}$ (\% predicted) & $85(24)$ & $109(15)$ & 24 (12 to 37$)$ & 0.0003 \\
\hline Peak HR (\% HRmax pred) & $95(9)$ & $101(6)$ & $6(1$ to 11$)$ & 0.02 \\
\hline Peak VE (\% MVV) & 74 (17) & $71(12)$ & $-3(-12$ to 6$)$ & 0.53 \\
\hline Lactate $(\mathrm{mmol} / \mathrm{l})$ & $9.8(2.9)$ & $11.7(3.1)$ & $1.9(-0.2$ to 4.0$)$ & 0.08 \\
\hline Dyspnoea cycle (points) & $5.9(1.9)$ & $4.9(2.0)$ & $-1.0(-2.2$ to 0.3$)$ & 0.14 \\
\hline Fatigue cycle (points) & $7.4(1.9)$ & $6.3(1.6)$ & $-1.1(-2.2$ to 0.0$)$ & 0.05 \\
\hline
\end{tabular}

\section{Steroids $v$ non-steroids in sarcoidosis}

Patients with sarcoidosis who were treated with corticosteroids in the 6 month period before testing $(\mathrm{n}=11$, median $5 \mathrm{mg} /$ day (IQR 2-18)) and those who were not $(\mathrm{n}=11)$ had comparable characteristics, muscle force (fig 3), and exercise capacity except for FVC (table 4) and IL-6 (table S2 in the online Appendix). Moreover, TNF- $\alpha$ and the SF-36 scale physical functioning tended to be different (table S3 in the online Appendix). When only the 11 patients with sarcoidosis who had not received oral corticosteroids in the 6 month period before testing were considered, there was still a reduction in quadriceps peak torque compared with healthy subjects $(\mathrm{p}<0.01)$.

\section{Correlations}

Correlations between functional tests in sarcoidosis To reduce the impact of confounding variables on the correlations, the values of the functional tests were normalised

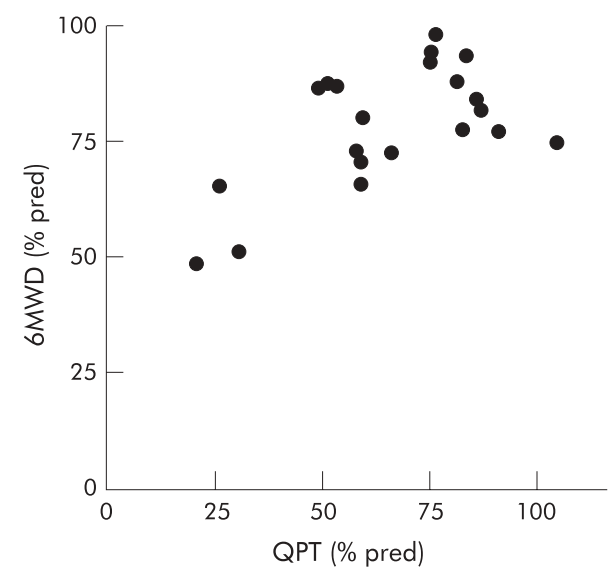

Figure 1 Correlation between muscle force and functional exercise capacity in patients with sarcoidosis. There was a positive correlation between quadriceps peak torque (QPT) and the distance walked in 6 minutes (6MWD) in patients with sarcoidosis. Both variables are expressed as a percentage of the predicted values (\% pred). for age, sex, height, and/or body weight by expressing them as a percent of the predicted values. Quadriceps peak torque was significantly associated with peak external work rate $(r=0.47, \mathrm{p}=0.03)$, the timed walking distance $(r=0.61, \mathrm{p}=0.003$, fig 1$)$, and with the Borg symptom scores for fatigue after the peak exercise test $\left(r_{\mathrm{S}}=-0.43, \mathrm{p}=0.05\right)$ and functional exercise test $\left(r_{\mathrm{S}}=-0.75, \mathrm{p}=0.0001\right)$. Neither FVC nor TLCO were correlated with peak external work rate $(r=0.38, \mathrm{p}=0.08$ and $r=0.37, \mathrm{p}=0.09$, respectively) or with the timed walking distance $(r=-0.01, \mathrm{p}=0.97$; and $r=0.18, \mathrm{p}=0.42$, respectively).

Correlations between functional tests, depression, and health status in sarcoidosis

Quadriceps peak torque was inversely correlated with depression $\left(r_{\mathrm{S}}=-0.50, \mathrm{p}=0.02\right)$. In addition, positive correlations were found with SF-36 scales physical functioning $\left(r_{\mathrm{S}}=0.70, \mathrm{p}=0.0004\right.$, fig 2$)$, physical role $\left(r_{\mathrm{S}}=0.59\right.$, $\mathrm{p}=0.006)$, pain $\left(r_{\mathrm{S}}=0.62, \mathrm{p}=0.003\right)$, vitality $\left(r_{\mathrm{S}}=0.44\right.$, $\mathrm{p}=0.04)$, social functioning $\left(r_{\mathrm{S}}=0.50, \mathrm{p}=0.02\right)$, and mental health $\left(r_{\mathrm{S}}=0.56, \mathrm{p}=0.01\right)$, and with the CRDQ domain fatigue $\left(r_{\mathrm{S}}=0.48, \mathrm{p}=0.03\right)$.

Neither FVC nor TLCo was correlated with depression $\left(r_{\mathrm{S}}=-0.07, \mathrm{p}=0.77\right.$; and $r_{\mathrm{S}}=-0.25, \mathrm{p}=0.27$, respectively $)$ or with the CRDQ domain fatigue $\left(r_{\mathrm{S}}=0.18, \mathrm{p}=0.45\right.$; and $r_{\mathrm{S}}=0.26, \mathrm{p}=0.27$, respectively), and they were only positively related to one SF-36 multiple item scale: physical functioning $\left(r_{\mathrm{S}}=0.46, \mathrm{p}=0.04\right.$, and $r_{\mathrm{S}}=0.42, \mathrm{p}=0.056$, respectively).

Depression and fatigue correlated strongly with most of the SF-36 scales, especially with those that indicate the extent to which physical health or emotional problems interfere with normal social activities (tables 4 in the online Appendix).

\section{Correlations with circulating anabolic and} inflammatory markers in sarcoidosis

Only IGF-I was positively related to maximal inspiratory pressure (expressed as \% predicted, $r_{\mathrm{S}}=0.45, \mathrm{p}=0.04$ ). Neither respiratory muscle forces nor skeletal muscle forces 
Table 3 Scores on questionnaires in patients with sarcoidosis and healthy subjects

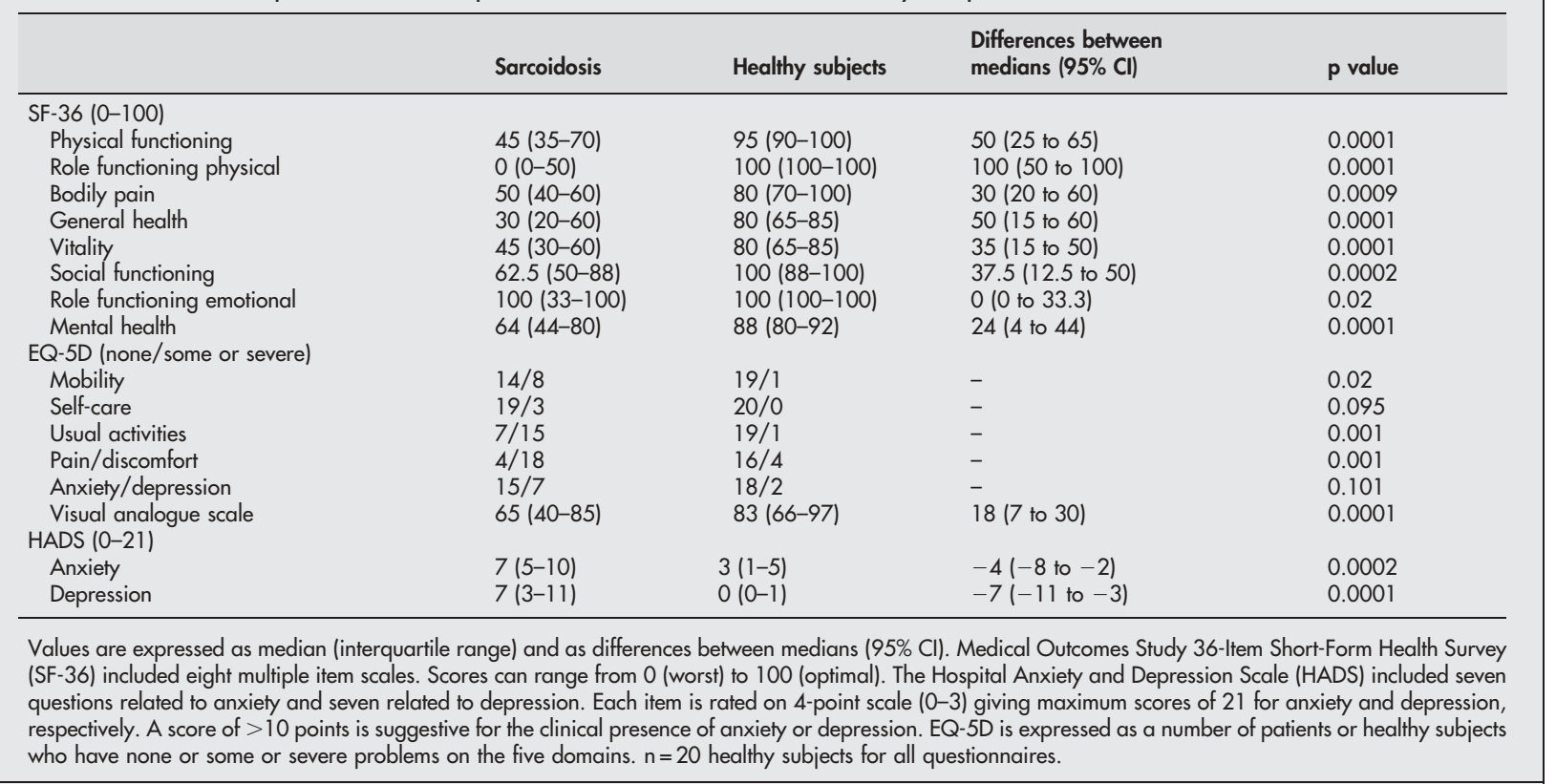

were significantly related to IGFBP-3, IL-6, CXCL8, TNF- $\alpha$, or to its receptors.

\section{Correlations with mean daily dose of corticosteroids in sarcoidosis}

Only in the patients who received oral corticosteroid treatment was quadriceps peak torque inversely related to the mean daily dose of corticosteroids received in the 6 months before testing $\left(\mathrm{n}=11, r_{\mathrm{S}}=-0.62, \mathrm{p}=0.04\right.$, fig 3$)$. Maximal inspiratory pressure $\left(r_{\mathrm{S}}=0.33\right)$, expiratory pressure $\left(r_{\mathrm{S}}=-0.24\right)$, and handgrip force $\left(r_{\mathrm{S}}=-0.46\right)$ were not related to the mean daily dose of corticosteroids in these patients $(\mathrm{p}>0.15)$.

\section{DISCUSSION}

This study is the first to show significant reductions in skeletal muscle force in patients of white ethnic origin with sarcoidosis who complain of fatigue accompanied by exercise intolerance, depression, and reduced health status. In fact,

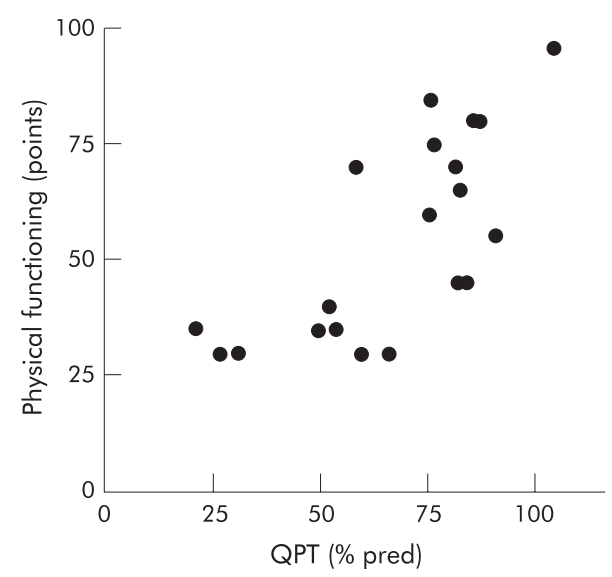

Figure 2 Correlation between muscle force and health status in patients with sarcoidosis. There was a positive correlation between quadriceps peak torque (QPT) and SF-36 scale physical functioning in patients with sarcoidosis. QPT is expressed as percentage predicted (\% pred) and physical functioning in arbitrary units (points).
FVC and TLCO which are commonly used to indicate functional impairment in sarcoidosis ${ }^{1}$ had weaker or nonsignificant correlations with these measurements.

\section{Muscle weakness in sarcoidosis}

According to the latest statement on sarcoidosis, proximal skeletal muscles weakness is "a common clinical manifestation". ${ }^{1}$ Nevertheless, the present study is the first to observe skeletal muscle weakness in a consecutive sample of patients with sarcoidosis. Our results are in contrast to those of Wirnsberger and co-workers who did find respiratory muscle weakness but not skeletal muscle weakness. ${ }^{5}$ This is unlikely to be due to differences in the healthy subjects who were of a similar age (mean 42 years), inspiratory muscle force (mean $-115 \mathrm{~cm} \mathrm{H}_{2} \mathrm{O}$ ), and handgrip force (mean $54 \mathrm{kgF}$ for men and $31 \mathrm{kgF}$ for women) to those in the study by Wirnsberger

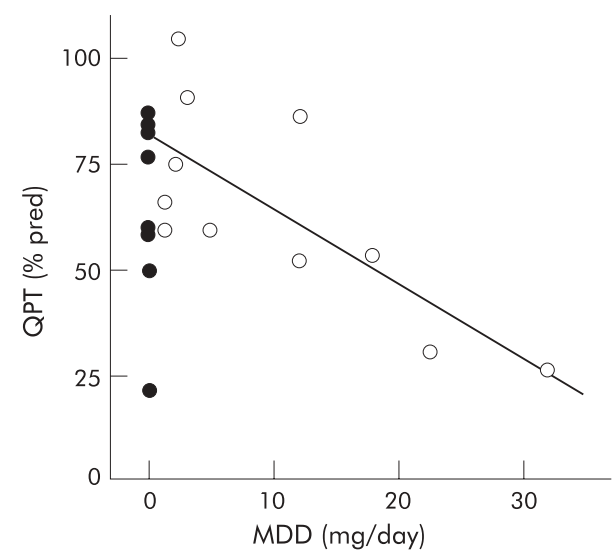

Figure 3 Correlation between mean daily dose of steroids and muscle force in patients with sarcoidosis. There was an inverse correlation between the mean daily dose of methylprednisolone equivalents (MDD) in the 6 month period before testing and quadriceps peak torque (QPT) in patients with sarcoidosis who received oral corticosteroids in the 6 month period before testing lopen circles $=M D D>0$; closed circles $=$ sarcoidosis patients with $M D D=0$ ). $M D D$ is expressed in $\mathrm{mg} /$ day and QPT as a percentage predicted (\% pred). 
Table 4 Characteristics and muscle force in patients taking steroids and those not taking steroids

\begin{tabular}{llll}
\hline & Taking steroids & Not taking steroids & $\begin{array}{l}\text { Differences between } \\
\text { means }(95 \% \text { Cl) }\end{array}$ \\
\hline BMI $\left(\mathrm{kg} / \mathrm{m}^{2}\right)$ & $26(4)$ & $29(6)$ & $3(-2$ to 7$)$ \\
FVC (\% predicted) & $91(17)$ & $111(16)$ & $21(6$ to 36$)$ \\
FEV $1 /$ FVC (\%) & $79(3)$ & $74(11)$ & $-6(-13$ to 2$)$ \\
TLCO (\% predicted) & $75(16)$ & $80(14)$ & $6(-7$ to 19$)$ \\
PImax (\% predicted) & $76(21)$ & $82(21)$ & $6(-13$ to 24$)$ \\
QPT (\% predicted) & $64(24)$ & $69(20)$ & $5(-15$ to 25$)$ \\
6MWD (m) & $608(121)$ & $603(146)$ & $-5(-124$ to 115$)$ \\
Peak $\mathrm{VO}_{2}(\mathrm{ml} / \mathrm{kg} / \mathrm{min})$ & $25(9)$ & $26(10)$ & 0.13 \\
\hline
\end{tabular}

Values are expressed as mean (SD) and as differences between means (with $95 \% \mathrm{CI}$ ).

$\mathrm{BMI}$, body mass index; FVC, forced vital capacity; $\mathrm{FEV}_{1}$, forced expiratory volume in 1 second; TLCO, carbon monoxide transfer factor; PImax, maximal inspiratory pressure; QPT, quadriceps peak torque; $6 \mathrm{MWD}$, distance walked in 6 minutes; $\mathrm{VO}_{2}$, oxygen uptake.

et al. ${ }^{5}$ The discrepancy may be explained by differences in the sarcoidosis patients studied. Only about $35 \%$ of the patients studied by Wirnsberger et al had self-reported complaints of fatigue $^{5}$ while all the patients in our study complained of fatigue. Patients with sarcoidosis who complained of fatigue had more pronounced respiratory muscle weakness, ${ }^{5}$ a lower fat free mass over body weight ratio, and they reported exercise intolerance and muscle pain more frequently than sarcoidosis patients without fatigue. ${ }^{15}$ Moreover, in the present study positive correlations of quadriceps peak torque with CRDQ domain fatigue and with SF-36 scale vitality were found in patients with sarcoidosis.

Skeletal muscle weakness in patients with sarcoidosis may be related to corticosteroid treatment. The mean daily dose of oral corticosteroids over the 6 months prior to the study was inversely associated with quadriceps peak torque in the 11 patients with sarcoidosis who received oral cortiocosteroids during this period (fig 3). Although at first this seems to be straightforward, ${ }^{17}{ }^{21}$ this finding is in contrast to several case reports of patients with sarcoidosis in whom normal or improved skeletal muscle function has been reported after treatment with high doses of oral corticosteroids. ${ }^{37-39}$ This clearly shows that the effects of oral corticosteroid treatment on skeletal muscle function in patients with sarcoidosis are equivocal. If sarcoid muscle involvement is present, then steroids may be beneficial. However, steroids may also have a detrimental effect by causing steroid induced myopathy. Future studies to explore the underlying cause of myopathy (corticosteroids, acute myositis, or granulomas) will be of great value for identifying factors that may induce skeletal muscle dysfunction in patients with sarcoidosis. The use of other techniques such as muscle biopsies, electromyography, nerve conduction, and additional blood analyses (such as creatine kinase and electrolytes) should also be considered. ${ }^{40}$

No differences were found in muscle force between patients who took steroids and those who did not (table 4, fig 3). Other factors may therefore contribute to the development of muscle weakness in sarcoidosis. In the present study co-morbidities such as chronic heart failure (no clinical cardiac history) and emaciation (lower limit 95\% CI of BMI in patients with sarcoidosis $22.0 \mathrm{~kg} / \mathrm{m}^{2}$ ) can be excluded as possible contributing factors to the generalised muscle weakness in these patients. The positive association between skeletal muscle weakness and the reduced median scores on the SF-36 scale role functioning physical suggests that physical inactivity might play a role in the development of skeletal muscle weakness in sarcoidosis. In fact, complaints of fatigue will probably reduce the day to day physical activities of patients. Consequently, reduced physical activities can induce general deconditioning which, in turn, contributes to increased perceived fatigue and more physical inactivity. Patients may thus end up in a negative vicious circle of deconditioning.
In addition to disuse, circulating levels of proinflammatory cytokines and of IGF-I may be involved in the development of muscle weakness..$^{19225}$ Nevertheless, in the present study skeletal and respiratory muscle weakness did not correlate with the circulating levels of IGF-I, IL-6, CXCL8, and TNF- $\alpha$ in patients with sarcoidosis. This may be due to the treatment with oral corticosteroids. ${ }^{41}$

\section{Exercise intolerance}

Functional and peak exercise capacities were significantly lower than in healthy subjects. Both have been reported before in sarcoidosis and are believed to be limited by the ventilatory and cardiocirculatory systems. ${ }^{6-10}$ The present study is the first to observe a positive correlation between skeletal muscle force and exercise tolerance in patients with sarcoidosis, irrespective of age, sex, height, and body weight. Skeletal muscle dysfunction may therefore contribute to exercise intolerance in sarcoidosis. Higher Borg symptom scores for leg fatigue after the functional and peak exercise test and their inverse relationships with quadriceps peak torque accentuated this. Patients with sarcoidosis in our study tended to have a higher heart rate for the same oxygen uptake (fig Sl online) which suggests physical deconditioning. This is in contrast to the findings of Delobbe and coworkers $^{7}$ who reported lower heart rates in patients with sarcoidosis for similar relative exercise intensities of the achieved peak oxygen uptake compared with healthy subjects. Nevertheless, after expressing their results for oxygen uptake in l/min, Delobbe et $\mathrm{al}^{7}$ also found higher heart rates for the same oxygen uptake in sarcoidosis patients as in healthy subjects (additional details are available in fig S2 online).

In chronic pulmonary and cardiac diseases skeletal muscle dysfunction significantly contributes to exercise intolerance. ${ }^{11}{ }^{12}$ Transcutaneous neuromuscular electrical stimulation $^{42}{ }^{43}$ and high intensity resistance training can partially restore these functional deficits. ${ }^{44}{ }^{45}$ Subsequent to the presence of skeletal muscle weakness and exercise intolerance, our results provide a clear rationale for investigating the effects of analogous training programmes in sarcoidosis. Besides improving health status, exercise capacity and skeletal muscle function, exercise training may even reduce clinical symptoms of fatigue, anxiety and depression ${ }^{46}$ and lower the circulating levels of TNF- $\alpha$ and its receptors. ${ }^{47}$

\section{Reduced health status}

Health status was significantly lower in patients with sarcoidosis than in healthy subjects (table 3). Similar scores on the SF-36 scale have previously been reported in patients with sarcoidosis. ${ }^{4}$ In the present study low SF-36 scores indicated that the physical and social daily activities of the patients were, to a great extent, limited by their perceived physical health or emotional problems, including 
accomplishing less than wanted..$^{31}$ The presence of fatigue in daily life was underlined by the difference on the CRDQ domain fatigue between patients with sarcoidosis and healthy subjects, which exceeded the minimal clinically important difference of 2 points used in patients with chronic lung disease. ${ }^{48}$

As shown previously, ${ }^{4}{ }^{5}$ several SF-36 scales were associated with FVC, TLCO and with respiratory muscle weakness in patients with sarcoidosis. In the present study, however, the correlations between skeletal muscle weakness, depression, fatigue, and SF-36 scales were clearly stronger.

\section{Methodological and statistical considerations}

The mechanisms causing skeletal muscle weakness in patients with sarcoidosis cannot be determined from the present data. Confounding factors (such as corticosteroid treatment, fatigue and physical inactivity) which may have influenced the main outcome (skeletal muscle force) were present in the sarcoidosis patients but not in the healthy subjects. Our control group may not therefore be ideal for determining the mechanisms causing skeletal muscle weakness in sarcoidosis. ${ }^{49}$ Nevertheless, the observation of skeletal muscle weakness in sarcoidosis patients who complain of fatigue is still valid and of clinical relevance.

The research setting and location may have led to biases in the selection of the patients. Sarcoidosis patients with the most severe complaints are more likely to be referred to a tertiary care setting. In addition, only patients who spontaneously report fatigue were included. Patients were all of white ethnic origin while fever, fatigue, and loss of body weight are known to be more frequently present in AfricanAmerican and Asian Indian patients with sarcoidosis. ${ }^{50}{ }^{51}$ The external validity of the study is therefore limited to patients of white ethnic origin with sarcoidosis who complain of fatigue. The findings of the present study need to be reproduced in a larger sample with ethnically diverse patients and with a longer follow up period so that the outcome of clinical care can be assessed.

At the start of the present study (around December 2001) no validated and reliable questionnaire was available to measure fatigue and health status in sarcoidosis. We therefore used the CRDQ domain fatigue and the SF-36, respectively. Recently, however, the Sarcoidosis Health Questionnaire has been validated and appears to be a promising instrument to measure disease specific health status in sarcoidosis. ${ }^{52}$ Significant correlations do not necessarily imply causal relationships. Moreover, statistically significant differences between groups need to be interpreted in the light of the number of comparisons that were made in the present study. Nonetheless, by setting the p value at 0.01 , only one out of 100 comparisons was expected to be statistically significant by chance. A priori, no power calculations were performed so non-significant comparisons between the groups may have been caused by a type II error.

\section{Clinical implications}

In addition to exercise tests which have been shown to be sensitive physiological measurements to assess the extent of disease in early radiographic stages of sarcoidosis, ${ }^{8}$ the present study underlines the importance of assessing skeletal muscle function in sarcoidosis patients with fatigue. Skeletal muscle force is related to exercise capacity and health status in these patients, and can therefore be seen as an additional measure of their functional status (defined as "the patient's ability to perform his/her normal level of function in several domains of daily living such as physiologic, psychologic and sociologic performance ${ }^{\prime 53}$ ). Hence, muscle force tests, exercise tests, and health status questionnaires provide additional valuable information on patients' functional status and merit inclusion in the screening and follow up of sarcoidosis patients with fatigue. This is in agreement with DeRemee ${ }^{54}$ who suggested that "the whole patient should be the object of our ministrations, not only pulmonary function or biochemical aberrations".

Physicians have to be aware that patients with sarcoidosis who complain spontaneously of fatigue can have explicit respiratory and skeletal muscle weakness, exercise intolerance, and reduced health status. Moreover, the present results underline again the complexity of sarcoidosis and the need for a multidisciplinary approach in the management of sarcoidosis patients with fatigue. ${ }^{55}$

We conclude that skeletal muscle weakness is present in sarcoidosis patients of white ethnic origin who complain of fatigue. Moreover, this study is the first to show correlations between skeletal muscle weakness, exercise intolerance, and reduced health status in these patients.

\section{ACKNOWLEDGEMENTS}

The authors thank physiotherapists D Van Campfort and P Neyrinck for their assistance in gathering the data and for recruiting healthy subjects; physiotherapists I Coosemans and V Barbier for testing all participants; Miss K Maes and Prof Dr G Gayan-Ramirez for handling the plasma samples; $\mathrm{Mr} \mathrm{W}$ Coopmans for determining circulating levels of IGF-I and IGFBP-3; biostatisticians A Komarek and S Cecere of the Biostatistical Center for their advice; and all the participants who graciously consented to participate in the study.

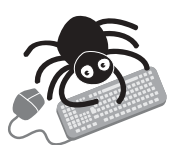

Additional information is given in the online Appendix and figs S1 and S2 available on the Thorax website at www.thoraxinl.com/supplemental.

\section{Authors' affiliations}

M A Spruit, M J Thomeer, R Gosselink, T Troosters, A J T Debrock, M G Demedts, M Decramer, Respiratory Rehabilitation and Respiratory Division, University Hospital Gasthuisberg, Leuven, Belgium

M A Spruit, R Gosselink, T Troosters, A J T Debrock, M G Demedts, $M$ Decramer, Department of Rehabilitation Sciences, Faculty of Physical Education and Physiotherapy, Katholieke Universiteit Leuven, Leuven, Belgium

A Kasran, Laboratory of Experimental Immunology, Faculty of Medicine, Katholieke Universiteit Leuven, Leuven, Belgium

Sources of financial support: 'Fonds voor Wetenschappelijk Onderzoek Vlaanderen' (FWO), Belgium, grant \#G.0237.01 and FWO Levenslijn grant \#7.0007.00. $\pi$ is a FWO postdoctoral fellow.

\section{REFERENCES}

1 Statement on sarcoidosis. Joint Statement of the American Thoracic Society (ATS), the European Respiratory Society (ERS) and the World Association of Sarcoidosis and Other Granulomatous Disorders (WASOG) adopted by the ATS Board of Directors and by the ERS Executive Committee, February 1999. Am J Respir Crit Care Med 1999;160:736-55.

2 Chang B, Steimel J, Moller DR, et al. Depression in sarcoidosis. Am J Respir Crit Care Med 2001;163:329-34.

3 Drent M, Wirnsberger RM, Breteler MH, et al. Quality of life and depressive symptoms in patients suffering from sarcoidosis. Sarcoidosis Vasc Diffuse Lung Dis 1998;15:59-66.

4 Chang JA, Curtis JR, Patrick DL, et al. Assessment of health-related quality of life in patients with interstitial lung disease. Chest 1999;116:1175-82.

5 Wirnsberger RM, Drent M, Hekelaar N, et al. Relationship between respiratory muscle function and quality of life in sarcoidosis. Eur Respir $J$ 1997; 10:1450-5.

6 Arcasoy SM, Christie JD, Pochettino A, et al. Characteristics and outcomes of patients with sarcoidosis listed for lung transplantation. Chest $2001 ; 120: 873-80$

7 Delobbe A, Perrault H, Maitre J, et al. Impaired exercise response in sarcoid patients with normal pulmonary function. Sarcoidosis Vasc Diffuse Lung Dis 2002; 19:148-53.

8 Medinger AE, Khouri S, Rohatgi PK. Sarcoidosis: the value of exercise testing. Chest 2001;120:93-101.

9 Miller A, Brown LK, Sloane MF, et al. Cardiorespiratory responses to incremental exercise in sarcoidosis patients with normal spirometry. Chest 1995; 107:323-9. 
10 Sietsema KE, Kraft M, Ginzton L, et al. Abnormal oxygen uptake responses to exercise in patients with mild pulmonary sarcoidosis. Chest 1992;102:838-45.

11 Anker SD, Swan JW, Volterrani M, et al. The influence of muscle mass, strength, fatigability and blood flow on exercise capacity in cachectic and non-cachectic patients with chronic heart failure. Eur Heart J 1997; 18:259-69.

12 Gosselink R, Troosters T, Decramer M. Peripheral muscle weakness contributes to exercise limitation in COPD. Am J Respir Crit Care Med 1996; 153:976-80

13 Paramothayan S, Jones PW. Corticosteroid therapy in pulmonary sarcoidosis: a systematic review. JAMA 2002;287:1301-7.

14 Silverstein A, Siltzbach LE. Muscle involvement in sarcoidosis. Asymptomatic myositis, and myopathy. Arch Neurol 1969;21:235-41.

15 Drent M, Wirnsberger RM, de Vries J, et al. Association of fatigue with an acute phase response in sarcoidosis. Eur Respir J 1999;13:718-22.

16 Ziegenhagen MW, Muller-Quernheim J. The cytokine network in sarcoidosis and its clinical relevance. J Intern Med 2003;253:18-30.

17 Barry SC, Gallagher CG. Corticosteroids and skeletal muscle function in cystic fibrosis. J Appl Physiol 2003;95:1379-84.

18 Bilici $M$, Koroglu MA, Cakirbay $H$, et al. Isokinetic muscle performance in major depressive disorder: alterations by antidepressant therapy. Int J Neurosci 2001;109:149-64.

19 Cicoira M, Bolger AP, Doehner W, et al. High tumour necrosis factor-alpha levels are associated with exercise intolerance and neurohormonal activation in chronic heart failure patients. Cytokine 2001;15:80-6.

20 De Becker $\mathbf{P}$, Roeykens J, Reynders $M$, et al. Exercise capacity in chronic fatigue syndrome. Arch Intern Med 2000;160:3270-7.

21 Decramer M, de Bock V, Dom R. Functional and histologic picture of steroidinduced myopathy in chronic obstructive pulmonary disease. Am J Respir Crit Care Med 1996; 153:1958-64.

22 Fulcher KY, White PD. Strength and physiological response to exercise in patients with chronic fatigue syndrome. J Neurol Neurosurg Psychiatry 2000;69:302-7.

23 Fernandez-Celemin L, Pasko N, Blomart V, et al. Inhibition of muscle insulin like growth factor I expression by tumor necrosis factor-alpha. Am J Physiol Endocrinol Metab 2002;283:E1 279-90.

24 Hambrecht R, Schulze PC, Gielen S, et al. Reduction of insulin-like growth factor-l expression in the skeletal muscle of noncachectic patients with chronic heart failure. J Am Coll Cardiol 2002;39:1175-81.

25 Spruit MA, Gosselink R, Troosters T, et al. Muscle force during an acute exacerbation in hospitalised patients with COPD and its relationship with CXCL8 and IGF-I. Thorax 2003;58:752-6.

26 Ziegenhagen MW, Schrum S, Zissel G, et al. Increased expression of proinflammatory chemokines in bronchoalveolar lavage cells of patients with progressing idiopathic pulmonary fibrosis and sarcoidosis. J Invest Med 1998:46:223-31.

27 Scadding JH. Prognosis of intrathoracic sarcoidosis in England: a review of 136 cases after 5 years' observation. BMJ 1961;2:1165-72.

28 Van den Berghe G, Baxter RC, Weekers F, et al. A paradoxical gender dissociation within the growth hormone/insulin- like growth factor I axis during protracted critical illness. J Clin Endocrinol Metab 2000;85:183-92.

29 Guyatt GH, Pugsley SO, Sullivan MJ, et al. Effect of encouragement on walking test performance. Thorax 1984;39:818-22.

30 Jones NL, Makrides L, Hitchcock C, et al. Normal standards for an incremental progressive cycle ergometer test. Am Rev Respir Dis 1985;131:700-8.

31 Ware JE, Snow KK, Kosinski M, et al. SF-36 health survey manual and interpretation guide. Boston, MA: The Health Institute, New England Medical Center Hospitals, 1993.

32 Dolan P. Modeling valuations for EuroQol health states. Med Care 1997;35:1095-108.
33 Zigmond AS, Snaith RP. The hospital anxiety and depression scale. Acta Psychiatr Scand 1983;67:361-70.

34 Guyatt GH, Berman LB, Townsend M, et al. A measure of quality of life for clinical trials in chronic lung disease. Thorax 1987;42:773-8.

35 Gardner MJ, Altman DG. Confidence intervals rather than P values: estimation rather than hypothesis testing. BMJ (Clin Res Ed) 1986;292:746-50.

36 Altman DG, Gore SM, Gardner MJ, et al. Statistical guidelines for contributors to medical journals. BMJ (Clin Res Ed) 1983:286:1489-93.

37 Hearth-Holmes M, Campbell GD Jr. Muscle weakness, fatigue, and joint pain in a 52-year-old woman. Chest 1995; 108:563-4.

38 Jamal MM, Cilursu AM, Hoffman EL. Sarcoidosis presenting as acute myositis. Report and review of the literature. J Rheumatol 1988;15:1868-71.

39 Mozaffar T, Lopate G, Pestronk A. Clinical correlates of granulomas in muscle. J Neurol 1998;245:519-24.

40 Chaudhuri A, Behan PO. Fatigue in neurological disorders. Lancet 2004;363:978-88

41 El Azab SR, Rosseel PM, de Lange JJ, et al. Dexamethasone decreases the proto anti-inflammatory cytokine ratio during cardiac surgery. $\mathrm{Br} J$ Anaesth 2002;88:496-501.

42 Bourjeily-Habr G, Rochester CL, Palermo F, et al. Randomised controlled trial of transcutaneous electrical muscle stimulation of the lower extremities in patients with chronic obstructive pulmonary disease. Thorax 2002;57:1045-9

43 Neder JA, Sword D, Ward SA, et al. Home based neuromuscular electrical stimulation as a new rehabilitative strategy for severely disabled patients with chronic obstructive pulmonary disease (COPD). Thorax 2002;57:333-7.

44 Simpson K, Killian K, McCartney N, et al. Randomised controlled trial of weightliffing exercise in patients with chronic airflow limitation. Thorax 1992:47:70-5.

45 Spruit MA, Gosselink R, Troosters T, et al. Resistance versus endurance training in patients with COPD and peripheral muscle weakness. Eur Respir J 2002; 19:1072-8

46 Emery CF, Schein RL, Hauck ER, et al. Psychological and cognitive outcomes of a randomized trial of exercise among patients with chronic obstructive pulmonary disease. Health Psychol 1998;17:232-40.

47 Adamopoulos S, Parissis J, Karatzas D, et al. Physical training modulates proinflammatory cytokines and the soluble Fas/soluble Fas ligand system in patients with chronic heart failure. J Am Coll Cardiol 2002;39:653-63.

48 Redelmeier DA, Guyatt GH, Goldstein RS. Assessing the minimal important difference in symptoms: a comparison of two techniques. J Clin Epidemiol 1996;49:1215-9.

49 Grimes DA, Schulz KF. An overview of clinical research: the lay of the land. Lancet 2002;359:57-61.

50 Baughman RP, Teirstein AS, Judson MA, et al. Clinical characteristics of patients in a case control study of sarcoidosis. Am J Respir Crit Care Med $2001 ; 164: 1885-9$.

51 Sharma SK, Mohan A, Guleria JS. Clinical characteristics, pulmonary function abnormalities and outcome of prednisolone treatment in 106 patients with sarcoidosis. J Assoc Physicians India 2001;49:697-704.

52 Cox CE, Donohue JF, Brown CD, et al. The Sarcoidosis Health Questionnaire: a new measure of health-related quality of life. Am J Respir Crit Care Med 2003; 168:323-9.

53 Lareau SC, Breslin EH, Meek PM. Functional status instruments: outcome measure in the evaluation of patients with chronic obstructive pulmonary disease. Heart Lung 1996;25:212-24.

54 DeRemee RA. Dysphoria and sarcoidosis. Sarcoidosis Vasc Diffuse Lung Dis 1998;15:21.

55 Drent $M$. Sarcoidosis: benefits of a multidisciplinary approach. Eur J Intern Med 2003;14:217-20. 